\title{
Multilingualism for Global Solutions and a Better World
}

\author{
Kathleen Stein-Smith \\ Fairleigh Dickinson University, Metropolitan Campus, Teaneck, NJ, USA
}

\begin{abstract}
This article examines the significance of multilingualism in finding global solutions and creating a better world. Language learning and multilingualism in the individual are discussed. The role of multilingualism in effectively addressing complex global issues is described. The nature of language skills and cultural knowledge in the individual and within international organizations is analyzed in terms of both policy structure and crisis communication, including the COVID-19 global pandemic, along with a brief overview of multilingualism in international business organizations. The US foreign language deficit is briefly discussed. Perspectives on foreign language education for a better world are provided, as are possibilities for increasing multilingualism for a better world.
\end{abstract}

Index Terms-multilingualism, global citizenship, language policy, intercultural competence, language learning

\section{INTRODUCTION}

Multilingualism -- the ability to communicate with other cultures in their language -- impacts both the individual and society, bringing personal and professional benefits to the individual, and bringing the benefits to society locally and globally. "Language is a critical instrument that shapes one's view of the world. Understanding the meaning of the words people use yields perhaps the most insight into cultural differences"(Adams \& Carfagna, 2006). More than half of the world population is bilingual or multilingual, using more than one language on a regular basis, yet the Anglosphere, or English-speaking world -- especially the United States -- lags behind in language skills. The conversation on multilingualism has often centered on the personal and professional benefits it brings to the individual and even on the economic and social benefits it brings to society, but significance of multilingualism in the development of an international mindset and global citizenship values, often referred to as a global or cosmopolitan identity, and in its value as a tool in working together with others for a better world, may not be discussed quite as often, but is perhaps even more important for our present and for our future.

Solutions to complex global issues are needed, and communication has never been more important. In a globalized and interconnected world, effective communication is essential in effectively addressing and resolving complex global issues, and multilingualism is an essential 21st century global skill. As "cooperation within and across borders is vital as we work to solve global challenges," multilingualism is a societal and global good (AMACAD, 2020). Multilingualism enables organizations, institutions, and governments to better reach stakeholders, clients and customers, and citizens. Perhaps most importantly, multilingualism empowers the individual to both develop an international mindset and global citizenship values, and also to communicate with others and to act as a global change agent. Multilingualism is part of daily life for more than half the world's population (Grosjean, 2010, 2020), and New York City is home to more than 700 languages (Ben Yahuda, 2021).

While the United Nations has 6 official languages -- Arabic, Chinese, English, French, Russian, and Spanish (in alphabetical order), and the European Union has multilingualism as a core value realized through plurilingualism, or an ability to use more than one language on a daily basis, the United States and much of the English-speaking or Anglophone world lags behind. In the US, only one in four Americans can hold a conversation in a language other than English, fewer than $20 \%$ of K-12 students study a foreign language, and only $7.5 \%$ of college and university students are enrolled in a class in a language other than English (McComb, 2001; American Councils, 2017; AMACAD, 2017).

It is clear that multilingualism is key to many global solutions, and the challenge is how to make it so. Although half the world population is multilingual, many still are not, and making known the importance of multilingualism and providing information as to how to make multilingualism more prevalent in any given society or community, are essential. Language skills are needed in international organizations, in business both internationally and locally, and in government (US Senate, 2012). The gap between supply and demand of language skills is not limited to the US, with the UK "suffering from a growing deficit in foreign language skills at a time when globally, the demand for language skills is expanding" (Tinsley, 2013).

Multilingualism has been found to be good for economic growth, and bilingual workers have higher incomes. "Multilingualism is good for the economy." and "countries that actively nurture different languages reap a range of rewards, from more successful exports to a more innovative workforce" (Hardach, 2018). While all languages are important, languages have been ranked in terms of their power, or influence, with English, Mandarin, Spanish, French, 
Chinese, and Russian, the top 6 (coinciding with the official languages of the US) (Chan, 2016), and Spanish, Chinese, and French are the most in demand among US employers (ACTFL, 2019). An earlier Bloomberg study found English, Chinese, and French to be the most useful languages for international business (English, 2011).

\section{LANGUAGE LEARNING AND MULTILINGUALISM IN THE INDIVIDUAL}

While the significance of multilingualism in global citizenship may appear obvious to many -- especially to foreign language and international educators, to language stakeholders in business and government, and especially to parents and communities, the relationship between multilingualism and global identity/citizenship remains relatively unexamined and little discussed. In addition to the personal and professional benefits generally associated with language skills, language learning also makes us more open to new ideas and experiences, and more tolerant (Thompson, 2016). There are two aspects in the examination of multilingualism in global citizenship that require special attention -- the role of multilingualism in the development of a cosmopolitan or global identity in the individual, and the use of multilingualism and knowledge of other cultures as a tool in effectively addressing complex global issues.

Within the context of language learning and multilingualism for a better world, language and culture cannot be separated. In addition to the traditional emphasis on proficiency, foreign language learning also includes learning about the culture with the goal of increasing intercultural competence (Sercu, 2006). In addition, language learning needs to include "intercultural competence, and language teachers need to become "teachers of language and culture" (Byram, 2009). Immersion is an especially beneficial environment for young language learners because "becoming bilingual leads to new ways of conceptualizing yourself and others. It expands your worldview, so that you not only know more, you know differently" (Williams, 2012).

The example of the foreign language teacher offers a unique perspective on the impact of language learning on identity, as language teachers typically spend extensive time living in, interacting with, and learning about the culture of their chosen language beyond the professional requirements. Many of these language and culture educators are deeply influenced in their worldview, values, lifestyle, and identity by their intense and lifelong relationship with another language and its culture (Grosjean, 2019). Multilingualism is a "universal good that can positively transform a child, a family, a school, a community, and even a country" (Jaumont, 2017).

The relationship between language skills and the development of a global identity is framed by the nature of the language learning process. Individuals may learn languages in a variety of manners, many beyond the traditional foreign language classroom -- as a heritage language, as a second language while residing in another country or regions, through literature, the arts and media, or in a social, family, or in a workplace setting, such as learning the language of a friend, of co-workers, or of a loved one or significant other. Language learning may, and often does, take place in an instructional setting, whether in-person or online, or within a formal institution and curriculum, an informal setting, or as an independent self-directed learner. Motivation has also been linked to success learning outcomes, with language learners with intrinsic motivation more likely to achieve better language skills (Dornyei, 2005).

Each of the methods of language learning affects the degree to which the acquisition of language skills impacts the identity and worldview of the individual, and it is interesting to note that the increase in the use of technology in language learning may have divergent impacts -- reducing the personal aspect of face-to-face instruction and informal conversation while increasing the availability of authentic language through text, media, and conversation. Heritage languages learners may develop a deeper knowledge, understanding, and appreciation of their heritage, leading to a more complex and nuanced personal cultural identity and to enduring interest in the other culture(s) reflecting their heritage. Learning another language due to having moved to another country or region impacts identity to varying degrees depending on the degree of integration or assimilation into the new culture of the individual. Those who come to a second language through an interest in another culture -- its literature, media, and the arts, etc. -- may acquire more advanced skills in some areas rather than others, the person singing opera acquiring better oral skills and the person interested in the literature better reading skills, etc. Those who learn culture in the workplace or from a friend or loved one may develop a better knowledge and appreciation of one aspect of the target culture than other, such as business language and office etiquette if learned in the workplace, or the terminology of a specific business function.

The question of curriculum is of major importance if the additional language is learned in a classroom or other formal setting, as it is possible to learn language skills in relative isolation if there is little in the way of a cultural component to the adopted curriculum. If the language is learned in a more informal setting, such as a conversation practice group or "language lunches," impact on identity and worldview may vary depending on the nature of the particular group. Independent self-directed learning is an interesting option to consider in terms of the development of both language skills and cultural knowledge, which may vary depending on the interests and insights of the learner ranging from strictly linguistic skills to in-depth cultural knowledge in one or more areas.

Multilingualism plays a significant role in the development of global identity, and lack of language skills limits this development (Gunesch, 2003). Access to foreign language learning and motivation are key factors in language learning, and foreign language curriculum emphasizing intercultural is essential in language learning for a better world (AMACAD, 2017; Dornyei, 2005; Sercu. 2006; Byram, 2009). However, it is equally important to bear in mind that multilingualism is a tool in global collaborations to make the world a better place rather than an end in itself. 


\section{The Role of Multilingualism as a Tool in Effectively AdDREssing Complex Global IsSuES -- ORganizations, Issues, AND LANGUAGE POLICY}

Beyond the impact of language and cultural learning on the personal cultural identity of the individual, the role of multilingualism as a tool in our personal and professional lives and in effectively addressing complex global issues includes but also transcends the obvious advantage of being able to communicate with others directly either in their own language, in the official language of an organization or gathering, in a third language decided upon for a specific event, or in response to a humanitarian crisis or disaster. Multilingualism, or the use of a variety of languages, can lead to greater acceptance and buy-in, increasing the likelihood of participation and successful outcome. In addition, the use of additional languages relevant to the setting can symbolize an openness to other cultures and can make aid more approachable to local populations, and less externally-driven to recipients (Garrido, 2019; Footitt, 2017; Lozinskiy, 2020). The role of multilingualism in addressing complex global issues is varied and multifaceted depending on locations, circumstances, and individuals, but falls into two general categories -- organizational structure and operations, and crisis and disaster response.

While the impact of language and languages on personal identity remains relatively unseen, the use of multilingualism can be highly visible in international organizations, events, and activities. Certainly the most recognizable global institution is the United Nations, which has 6 official languages -- Arabic, Chinese, English, French, Russian, and Spanish (in alphabetical order), with English and French the working languages of the UN Secretariat. Along with other languages that may also be used in UN publications and activities, these languages play an important role in the ongoing work of the UN. Examples of multilingualism at work include the Sustainable Development Goals, the cornerstone of the 2015-2030 UN global development agenda. While all of the Goals involve critical issues encompassing the world population, it is Goal 17, "Partnerships for the Goals," which most directly addresses the need for partnerships, collaborations, teamwork, and the multilingual skills needed to achieve all the Goals.

However, it is important to remember that while the United Nations has 6 official languages, the European Union has over 20 official languages but only a few working languages and embraces multilingualism as a core value, and plurilingualism as the actualization of language use in a wide variety of authentic settings. Other well-known examples of multilingualism in action at the global level include the International Olympic Committee, whose official languages are French and English, along with the local language of the current games. On a regional international level, the European Union, reflecting the power of its core value of multilingualism, considers the official languages of all member states as official languages, and its implementation of multilingualism is known as plurilingualism, or the ability to function effectively in other languages in a variety of settings. Confirming the importance of multilingualism and plurilingualism, in 2021, the "Executive Board of the Conference on the Future of Europe, comprising representatives from the European Parliament, the Council of the European Union and the European Commission, is launching the multilingual digital platform for the Conference on the Future of Europe." This initiative has the goal of empowering "all EU citizens to contribute to shaping their own future and that of Europe as a whole." It is available in 24 languages, "allowing citizens from across the Union to share and exchange their ideas and views through online events" (European Interest, 2021). The above-mentioned organizations are just a few examples of multilingualism in organizational structure and operation that include organizations like the Red Cross and Médecins sans Frontières/ Doctors without Borders, among others.

Beyond the ability to communicate directly with the other, the reasons for this focus on multilingualism at the global and international level include the wide array of benefits of bilingualism/multilingualism in terms of problem-solving and decision-making, along with diversity and divergent thinking (Livermore, 2016; Kharkurin, 2012). International initiatives and multilingual transnational teams have additional assets to bring to the task at hand. However, even more importantly, the use of a variety of languages can symbolize openness to other cultures and an intercultural perspective on the significance of aid in different cultures (Garrido, 2019; Footitt, 2017; Lozinskiy, 2020).

While the role of multilingualism in achieving the Sustainable Development Goals has already been discussed, climate change is another issue demanding a global response. The role of languages and multilingualism includes the necessity of making relevant news from around the world available to the largest audience in multiple languages and from a variety of perspectives, as well as making content produced in a particular language available to all. As lack of information can impede effective action against climate change, translation of key information and data can be of critical importance. As trust and confidence are key to buy-in, availability of information in local languages can increase buy-in and participation in initiatives. For all major global issues, education is an important component in an effective global response, and educational materials also need to be made available in a variety of languages.

Global health is certainly another area of universal concern, and multilingual communication is "an essential tool for improving global health," and the World Health Organization is an excellent example of an international organization with global health as its mission. The approach to multilingualism at the WHO is communication- based, as "multilingual communication bridges gaps and fosters understanding between people. It allows WHO to more effectively guide public health practices, reach out to international audiences, and achieve better health outcomes worldwide." In terms of the languages used, "while WHO gives priority to its official languages, it recognizes that the world's people live and work in many more. In order to broaden its reach to these audiences, WHO licenses external entities to translate and publish its health information in other languages." In its proactive approach to languages used in 
order to reach a larger audience and to increase buy-in, "WHO is always seeking opportunities to expand its multilingual information, and external publishers are key partners in this process. As a result of these partnerships, WHO publications have been translated and published in over 63 different languages." As a result, "a multilingual WHO is better equipped to communicate health messages, to produce and disseminate health information and to generate, share and use knowledge about health in an equitable manner. It is also better placed to meet today's major public health challenge: strengthening health systems in order to provide essential health care for all." (WHO, 2021; WHO, 2021a).

"Multilingual crisis communication has emerged as a global challenge during the COVID-19 pandemic" (Piller, Zhang, \& Li, 2020). The ongoing need for a multilingual approach to global health has been highlighted by the COVID19 pandemic, which has underscored the interconnectedness of the globalized world and the need for health information and responses in multiple languages and also the potential for marginalization of minority languages and their communities. This has been especially important in encouraging communication, but also in preventing misinformation and miscommunication due to language differences and the possibly dire consequences that may result. "Multilingual crisis communication has emerged as a global challenge during the COVID-19 pandemic. Global public health communication is characterized by the large-scale exclusion of linguistic minorities from timely high-quality information. The severe limitations of multilingual crisis communication that the COVID-19 crisis has laid bare result from the dominance of English-centric global mass communication; the longstanding devaluation of minoritized languages; and the failure to consider the importance of multilingual repertoires for building trust and resilient communities" (Piller, Zhang, \& Li, 2020). An example of this would be the lack of French used in officially bilingual Canada's early COVID responses in 2020 (AFP in Ottawa, 2020; Chouinard \& Normand, 2020).

The key to sustainable multilingualism in both organizational structure and operations, and especially in crisis response is a language policy that is both known to all parties and is clearly-written to provide guidance in the widest variety of circumstances. In addition, in order to avoid overrides and suspensions during emergency situation, its invariability must be clear, with strict accountability for any lapses, especially those which may impact on language rights of individuals and groups and on the public welfare.

\section{The Role OF Multilingualism in InTERnational Business ORGANizATions}

Multilingualism plays an essential role in business both globally and locally, in terms of doing business with companies in other countries as well as serving local communities where another language is prevalent. Beyond direct communication, language and cultural skills play a role in supporting effective problem-solving and decision-making, innovation, and harmony externally with clients and customers, and internally, among the organization's personnel. Its economic benefit brings the societal good of a better quality of life (Hogan-Brun, 2017).

It has been reported that in the US "9 out of 10 U.S. employers rely on employees with language skills other than English; 56\% say their foreign language demand will increase in the next 5 years; $47 \%$ state a need for language skills exclusively for the domestic market; 1 in 3 language-dependent U.S. employers report a language skills gap; and 1 in 4 U.S. employers lost business due to a lack of language skills" (ACTFL, 2019). In addition, the demand for bilingual workers in the US is rising, with demand for bilingual workers in the United States having more than doubled between 2010 and 2015 (NAE, 2017). The global language industry has an estimated value of \$50B (Gala-Global, 2021). . In terms of the economic impact of language skills, Switzerland has reported a $10 \%$ benefit from multilingualism, while the UK has reported a loss of $3.5 \%$ due to lack of language skills. In Florida and in Canada, bilingual workers have higher earnings (Hardach, 2018). However, the role of multilingualism as a social and economic benefit transcends corporate and individual earnings, and impacts society as a whole in terms of lessening poverty and improving the quality of life.

\section{The Many Languages One World Global Youth Forum (Mlow) -- The Significance Of Multilingualism IN THE DEVELOPMENT OF GLOBAL CITIZENSHIP}

The Many Languages One World Global Youth Forum (MLOW) is a wonderful example of the use of multilingualism as a tool to create a better world. An initiative of the UN Academic Impact, MLOW has examined the significance of multilingualism in the development of a global citizenship mindset and values (United Nations, 2017). Beginning with an essay contest on this topic, college and university student winners were invited to participate in a week-long global youth forum on a US campus near the UN. During this time, students lived in a global and multilingual community, interacting informally as they developed presentations which they would present in the UN General Assembly on action plans to implement the Sustainable Development Goals in their local community or institution. The emphasis on achievable action plans is in alignment with the value of multilingualism as a tool for effecting change and working for a better world.

The key to this initiative was the use of a learned second language that was also one of the official languages of the UN for both the entry essay and the UN presentation. MLOW participants have developed lasting relationships, remaining in contact through social media and local mini-reunions, and have demonstrated continuing commitment and 
involvement in global initiatives and through ongoing participation in UN and international events with the goal of making a better world using their multilingual skills.

\section{ENCOURAGING MULTILINGUALISM FOR A BETTER WORLD}

Multilingualism exists in a wide variety of governments, as well as within organizations working for a better world, and language policy provides a legal framework that tends to foster and encourage multilingualism in several ways -- by promoting interest and a public conversation about languages and language learning, and by strengthening language programs through funding and other types of incentivization. It is interesting to note the extent to which the European Union, with its core value of multilingualism and goal of plurilingual skills, has been able to encourage language learning in school from an early age, and through opportunities for work/internships and study abroad.

In order to foster and encourage multilingualism, a broad coalition of language educators and language stakeholders including business and government, and parents and communities, is needed. In terms of education, not all US students have access to this early start to foreign language learning (AMACAD, 2017), and a first step is to ensure that all interested students have the opportunity to learn an additional language from the earliest age, whether through a traditional foreign language program or through immersion. Although languages can be learned at any age, an early start and immersion learning are wonderful advantages.

It is equally important to develop sustainable motivation. Another challenge to language learning and to multilingualism in the US is that many US students may believe that, as English is the global lingua franca, it is not necessary to learn other languages, but the reality is that only one quarter of the world population speaks English and that multilingualism is not only our future, but also our present (British Council, 2013; Montlaur, 2019).

Effective responses to these challenges include advocacy for foreign language and immersion programs beginning at the earliest grade levels, pre-professional learning and K-16 collaborations at the high school level, and interdisciplinary collaborations and pre-professional learning at the college and university level, along with intercultural understanding and global learning at all levels.

Beyond the classroom, it is necessary to highlight the value of languages and multilingualism, through the media and public conversation and through communities where a variety of heritage languages are prevalent. In order to promote and to defend language learning, advocacy is needed, and in addition, beyond the classroom, a public conversation including parents and communities is essential in order to bring language learning -- and language use -- into our daily lives.

\section{CURRENT TRENDS AND Future DiRECTIONS}

Multilingualism is on the rise -- in the globalized and interconnected world, and in our local communities and neighborhoods. More than half of the world population is multilingual, and more than 70M Americans speak a language other than English in the home (Ryan, 2013). While many may believe that English, serving as a global lingua franca, is sufficient, that is not the case (AMACAD, 2020).

Complex global issues including the Sustainable Development Goals (SDGs), environmental issues and climate change, as well as global health and COVID, require global solutions. Multilingualism empowers both individuals and organizations to work more collaboratively and effectively toward global solutions.

Challenges include the rise in English as a perceived global language, and the resulting reluctance of English speakers to learn and to use additional languages. Solutions include an early start to foreign language education known in the US as FLES; bilingual education and immersion, which use more than one language of instruction; and multilingual education, which puts the mother tongue first in instruction for the young learner.

At the end of the day, "there are limits to an individual's cosmopolitan development if he or she does not have a set of languages to start with" (Gunesch, 2003). Whether as an individual or an organization desirous of making the world a better place, the ability to bring language skills to the table and to the task are part of the skills set of the 21 st century global citizen.

\section{CONCLUSIONS}

Many still believe that English is the global lingua franca, despite the fact that $75 \%$ of the world population does not speak English (British Council, 2013). However, "depending on the circumstances, conversations across boundaries can be delightful, or just vexing: what they mainly are, though, is inevitable" (Appiah, 2006). Depending on our vision of the world, we can envision an English-only world, with English as the global language and the resulting commodification of English, or a multilingual world with many voices reflecting diverse worldviews (Cameron, 2012; Montlaur, 2019). While the choice may be ours, the decision will inevitably impact our ability to work together to make the world a better place.

If we can develop a language policy to foster and encourage language learning and use, ensure that all our children have the opportunity to learn one or more additional languages, and incorporate intercultural understanding and appreciation into foreign language learning and the use of languages other than English, our children will have the 
linguistic skills and cultural knowledge needed to engage effectively with the world community as global citizens and play a role in global solutions and in making the world a better place.

\section{REFERENCES}

[1] Adams, J.M. \& Carfagna, A. (2006). Coming of Age in a Globalized World: The Next Generation. Westport, CT: Kumarian.

[2] AFP in Ottawa (AFP Ottawa). (2020). Justin Trudeau admits failure to uphold French language during pandemic.https://www.theguardian.com/world/2020/apr/28/justin-trudeau-canada-french-language-pandemic (accessed 05/5/2021).

[3] American Academy of Arts \& Sciences (AMACAD). (2017). America's Languages: Investing in Language Education for the 21st Century. https://www.amacad.org/publication/americas-languages (accessed 05/5/2021).

[4] American Academy of Arts \& Sciences (AMACAD). (2020). The Importance of Languages in Global Context: An International Call to Action. https://www.amacad.org/news/global-languages-importance (accessed 05/5/2021).

[5] American Council on the Teaching of Foreign Language (ACTFL). (2019) Making Languages Our Business. https://www.leadwithlanguages.org/language-advocacy/publications/ (accessed 05/5/2021).

[6] American Councils for International Education. (2017). The National K-12 Foreign Language Enrollment Survey Reporthttps://www.americancouncils.org/news/announcements/new-report-world-language-study-us-k-12-schools (accessed 05/5/2021).

[7] Appiah, K.A. (2006). Cosmopolitanism: Ethics in a World of Strangers. New York: Norton.

[8] Ben Yahuda, A. (2021). This interactive map highlights the 700 languages spoken in NYC. https://www.timeout.com/newyork/news/this-interactive-map-highlights-the-700-languages-spoken-in-nyc-041921 (accessed 05/5/2021).

[9] Bradley, S. (2008). Languages generate one tenth of Swiss GDP. https://www.swissinfo.ch/eng/languages-generate-one-tenthof-swiss-gdp/7050488 (accessed 05/5/2021).

[10] British Council. (2013). The English Effect. https://www.britishcouncil.org/research-policy-insight/policy reports/the-englisheffect (accessed 05/5/2021).

[11] Byram, M. (2009). Intercultural Competence in Foreign Languages The Intercultural Speaker and the Pedagogy of Foreign Language Education. Deardorff, D., ed. The SAGE handbook of intercultural competence. Thousand Oaks, CA: SAGE.

[12] Cameron, D. (2012). The commodification of language: English as a global commodity. Nevalainen, T, \& Traugott, E.C. eds. The Oxford Handbook of the History of English. Oxford, UK: Oxford UP.

[13] Chan, K. (2016). These are the most powerful languages in the world. https://www.weforum.org/agenda/2016/12/these-are-themost-powerful-languages-in-the-world/ (accessed 05/5/2021).

[14] Chouinard, S. \& Normand, M. (2020). Talk COVID to Me: Language Rights and Canadian Government Responses to the Pandemic. Canadian Journal of Political Science https:/www.ncbi.nlm.nih.gov/pmc/articles/PMC7231660/ (accessed 05/5/2021).

[15] Dornyei, Z. (2005). The Psychology of the Language Learner: Individual Differences in Second Language Acquisition. London: Routledge.

[16] English, Chinese, French most useful for business. (2011). https://www.languagemagazine.com/english-chinese-french-mostuseful-for-

business/\#: :text=After\%20English\%2C\%20Chinese\%20is\%20the,English\%20based\%20on\%20business\%20usefulness. (accessed 05/5/2021).

[17] European Interest. (2021). Conference on the Future of Europe: Launch of the Multilingual Digital Platform. https://www.europeaninterest.eu/article/conference-on-the-future-of-europe-launch-of-the-multilingual-digital-platform/ (accessed 05/5/2021).

[18] Footitt, H. (2017). International aid and development: hearing multilingualism, learning from intercultural encounters in the history of OxfamGB. Language and Interculture Communication $\quad$ v. 17 no. 4 https://www.tandfonline.com/doi/full/10.1080/14708477.2017.1368207 (accessed 05/5/2021).

[19] Garrido, M. (2020). Language investment in the trajectories of mobile, multilingual humanitarian workers. International Journal of Multilingualism v.17 no. 1 https://www.tandfonline.com/doi/abs/10.1080/14790718.2020.1682272 (accessed $05 / 5 / 2021)$.

[20] Globalization and Localization Association. (Gala-Global). (2021). Knowledge Center: About the Industry. https://www.galaglobal.org/knowledge-center/about-the-industry (accessed 05/5/2021).

[21] Grosjean, F. (2010, 2020). Bilingualism's Best Kept Secret. https://www.psychologytoday.com/us/blog/lifebilingual/201011/bilingualisms-best-kept-secret (accessed 05/5/2021).

[22] Gunesch, K. Multilingualism and Cosmopolitanism. (2003). Tokuhama-Espinosa, T. ed. The Multilingual Mind: Issues Discussed by, for, and about People Living with Many Languages. Westport, CT: Praeger.

[23] Hardach, S. (2018). Speaking more than one language can boost economic growth. https://www.weforum.org/agenda/2018/02/speaking-more-languages-boost-economic-growth/ (accessed 05/5/2021).

[24] Hogan-Brun, G. (2017). Linguanomics: What is the Market Potential of Multilingualism? NY: Bloomsbury.

[25] Jaumont, F. (2017). The Bilingual Revolution: The Future of Education Is in Two Languages. NY: TBR.

[26] Kharkhurin, A. (2012). Multilingualism and Creativity. Bristol, UK: Multilingual Matters.

[27] Livermore, D. (2016). Driven by Difference: How Great Companies Fuel Innovation through Diversity. NY: AMACOM.

[28] Lozinskiy, N. (2020). Multilingualism in the United Nations System: Report of the Joint Inspection Unit. https://www.unjiu.org/sites/www.unjiu.org/files/jiu_rep_2020_6_english.pdf (accessed 05/5/2021).

[29] McComb, C. (2001). About One in Four Americans Can Hold a Conversation in a Second Language https://news.gallup.com/poll/1825/about-one-four-americans-can-hold-conversation-second-language.aspx (accessed 05/5/2021). 
[30] Modern Language Association (MLA). (2019). Enrollments in Languages Other Than English in United States Institutions of Higher Education https://www.mla.org/Resources/Research/Surveys-Reports-and-Other-Documents/Teaching-Enrollmentsand-Programs/Enrollments-in-Languages-Other-Than-English-in-United-States-Institutions-of-Higher-Education (accessed 05/5/2021).

[31] Montlaur, B. (2019). Do you speak my language? You should. https://www.nytimes.com/2019/03/26/opinion/learn-foreignlanguage.html (accessed 05/5/2021).

[32] New American Economy (NAE). (2017). Not Lost in Translation: The Growing Importance of Foreign Language Skills in the US Job Market. https://research.newamericaneconomy.org/report/not-lost-in-translation-the-growing-importance-of-foreignlanguage-skills-in-the-u-s-job-market/ (accessed 05/5/2021).

[33] Piller, I., Zhang, J., \& Li, J. (2020). Linguistic diversity in a time of crisis: Language challenges of the COVID-19 pandemic. https://www.degruyter.com/document/doi/10.1515/multi-2020-0136/html (accessed 05/5/2021).

[34] Ryan, C. (2013). Language Use in the United States: 2011. https://www.census.gov/library/publications/2013/acs/acs-22.html (accessed 05/5/2021).

[35] Sercu, L. (2006). The foreign language and intercultural competence teacher: the acquisition of a new professional identity. Intercultural Communication v 17 no. 1. p. 55-72.

[36] Thompson, A. (2016). Learning a language has a lot of benefits, including making you more tolerant. https://www.weforum.org/agenda/2016/12/learning-a-language-has-a-lot-of-benefits-including-making-you-more-tolerant (accessed 05/5/2021).

[37] Tinsley, T. (2013). Languages: The State of the Nation. https://www.thebritishacademy.ac.uk/documents/2601/Languagesstate-of-the-nation-demand-supply-language-skills-UK-2013.pdf (accessed 05/5/2021).

[38] United Nations. (2017). Many Languages One World. https://www.un.org/youthenvoy/2017/02/many-languages-one-worldstudent-essay-contest-deadline-16-march/ (accessed 05/5/2021).

[39] US Senate. (2012). A National Security Crisis: Foreign Language Capabilities in the Federal Government. https://www.govinfo.gov/content/pkg/CHRG-112shrg75214/html/CHRG-112shrg75214.htm (accessed 05/5/2021).

[40] Williams, T.F. (2012). What the research tells us about immersion. https://asiasociety.org/china-learning-initiatives/whatresearch-tells-us-about-immersion (accessed 05/5/2021).

[41] World Health Organization (WHO). (2021). Fighting misinformation in the time of COVID-19, one click at a time. https://www.who.int/news-room/feature-stories/detail/fighting-misinformation-in-the-time-of-covid-19-one-click-at-a-time (accessed 05/5/2021).

[42] World Health Organization (WHO). (2021a). Multilingualism and WHO. https://www.who.int/about/who-weare/multilingualism (accessed 05/5/2021).

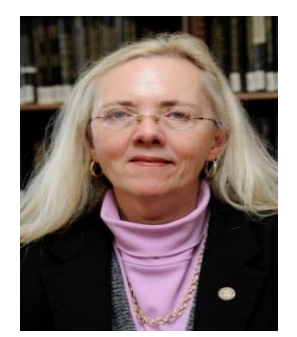

Kathleen Stein-Smith, PhD, Chevalier dans l'Ordre des Palmes académiques, is a dedicated foreign language educator and advocate.

She serves as Chair of the AATF (American Association of Teachers of French) Commission on Advocacy and as a member of the ATA Education and Pedagogy Committee and the MLA Delegate Assembly. She is also active in foreign language education associations, including the NECTFL Advisory Council, CSCTFL Advisory Council, and as a SCOLT sponsor.

She has presented at numerous professional conferences at the state, regional, and national level, is the author of five books and numerous articles about the foreign language deficit and the importance of multilingualism, has given a TEDx talk on the U.S. foreign language deficit, has been interviewed by press and radio, and maintains a blog, "Language Matters." 